\title{
Consumo digital e teoria de prática: uma abordagem possível
}

\section{Digital consumption and practice theory: a possible approach}

\author{
Sandra Portella Montardo \\ Doutora em Comunicação Social (PUCRS-2004). Fez estágio de doutorado na Université René Descartes, Paris V - Sorbonne. \\ Professora e pesquisadora do Programa de Pós-Graduação em Diversidade e Inclusão, do Programa de Pós-Graduação em \\ Processos e Manifestações Culturais, do Mestrado Profissional em Indústria Criativa e do Curso de Publicidade e Propaganda na \\ Universidade Feevale. \\ <sandramontardo@feevale.br>
}

\section{RESUMO}

Este artigo tem por objetivo conceituar consumo digital articulado a performance em sites de redes sociais. Um levantamento do estado da arte sobre o tema revela que, em geral, aborda-se o tema do consumo digital sem conceituá-lo, referindo-se a ele apenas como apropriações. Para tanto, este estudo recorre à Teoria de Prática como substrato teórico para a reflexão aqui pretendida. Frente a isso, o artigo está organizado da seguinte forma: 1) Teoria de Prática e sua relação com os estudos de mídia; 2) levantamento de estudos sobre práticas de mídia digital elaborados a partir dessa filiação teórica; 3) proposição de um conceito de consumo digital. Percebe-se que o consumo digital entendido pela Teoria de Prática, por um lado, não consiste em uma prática e, por outro, possibilita a prática da socialização online.

\begin{abstract}
This article aims to conceptualize digital consumption linked to social media sites. A research on the state of the art on this subject reveals that, in general, one approaches the digital consumption issue without previously conceptualizing it, regarding it as assumptions only. For this purpose, it resorts to the Practice Theory as theoretical support for the reflection intended by this work. This article is organized in three sections: 1) Practice Theory and its relation with media studies; 2) mapping of studies on practices of social media, all of which elaborated from this theoretical framework; 3) proposition of a concept of digital consumption. One may observe that, on one hand, the digital consumption as assumed by the Practice Theory is not a practice properly, and, one the other hand,enables the practice of socialization online.
\end{abstract}

\section{Introdução}

Um artigo anterior (2013) ocupou-se da verificação da pertinência da articulação de 3 dimensões para o estudo de consumo digital, quais sejam consumo, performance e sites de redes sociais, a partir de levantamento bibliográfico. Nesse estudo, três aspectos ressaltados por Barbosa (2009) quanto ao conceito de consumo revelaram-se pertinentes para a proposição dessa articulação. Nesses termos, em primeiro lugar, a autora (2009) afirma que mais do que apenas a reprodução física e social, o consumo desempenha função auxiliar no processo de "descoberta" ou "constituição" de nossa subjetividade e identidade. Em segundo lugar, destaca-se que, mesmo sem fazer menção 
explícita à performance, esse conceito de consumo permite algumas associações nessa direção por interpretar consumo como mecanismo social produtor de sentidos e de identidades, assim como estratégia de diferenciação de grupos, por exemplo. Quanto a isso, Campbell (2009) ainda complementa que não é o simples fato de adquirir algo que faz com que nos tornemos alguém, mas sim, a forma pela qual nos apropriamos de determinados bens e serviços é que confere a implicação entre consumir e ser alguém. Finalmente, um terceiro aspecto referido por Barbosa (2009) mostrou-se central para o entendimento do consumo digital, qual seja, que acesso a determinados bens e serviços possa ser interpretado como consumo, de modo que este não consista, necessariamente, na aquisição de um bem. Exemplo disso, seria, por exemplo, o acesso via streaming de um vídeo no You Tube ser considerado como consumo.

Uma vez que o foco deste projeto é o consumo compreendido como performance em sites de redes sociais, procedeu-se por uma busca que localizou apenas artigos referentes a consumo e performance nesses ambientes (Sá e Polivanov, 2012; Sá e Holzbach, 2010; Amaral, 2011; Amaral e Monteiro, 2012), deixando-se de fora outras abordagens sobre consumo digital. Nesses estudos, consumo era visto, adequadamente, como sinônimo de apropriação em termos de ações em sites de redes sociais que estabelecem a mediação entre as interações dos usuários, envolvendo performance de músicos e de fãs de música. Tratava-se, assim, de estudos de caso sobre consumo digital, como alguns dos orientados ou conduzidos nesta pesquisa, no campo da moda (Corrêa, 2012) e do ciberativismo (Montardo, 2013). Nascimento (2010), por sua vez, pesquisa a performance e a exposição de si nos sites Orkut e Facebook e, apesar de envolver o consumo de conteúdo digital nessas ações, a autora (2010) não privilegia este ponto.

Conforme já foi posto, não consta em nenhum desses estudos um conceito mais específico de consumo digital, sendo que o mesmo era presumido em interações em torno de conteúdos em plataformas digitais. Em todos os casos, chama a atenção que ações como acesso, disponibilização e armazenamento de conteúdo digital sejam considerados, indistintamente como consumo, o que faz questionar pelo elemento em comum que essas ações apresentam nesse sentido. Frente a isso, emergiu a necessidade de se propor um conceito de consumo digital que contemplasse essas e que pudesse ser estendido a outros usos de conteúdo digital em sites de redes sociais.

A busca por artigos que relacionassem consumo e performance, mesmo que em ambiente off-line, trouxe a contribuição de Warde (2005), intitulada Consumption and Theories of Practice. A partir deste artigo, a Teoria de Prática foi investigada e revelou-se pertinente para a elaboração de um conceito de 
consumo digital que levasse em conta a questão da performance em sites de redes sociais.

Frente a isso, esse artigo tem por objetivo propor um conceito de consumo digital a partir da Teoria de Prática. Para tanto, esta pesquisa está organizada da seguinte forma. Em um primeiro momento, faz-se um levantamento bibliográfico sobre Teoria de Prática, e sobre estudos de mídia e de mídia digital elaborados a partir dela. E, por fim, propõe-se um conceito de consumo digital a partir dessa Teoria, recuperando-se conceitos-chave de performance e de socialização online para tanto.

\section{Teoria de prática e estudos de mídia digital}

De acordo com Postill (2010, p. 6) a teoria de prática consiste em um conjunto de textos produzidos por pensadores que adotam uma definição frouxa de "abordagem de prática". Com isso, pode-se dizer que a Teoria de Prática não representa um campo unificado e coerente de estudos, definindose como "um corpo de trabalhos sobre o trabalho do corpo" (Postill, 2010, p.11). Nesse sentido, continua o autor (2010, p.11), o corpo humano consiste no nexo de práticas que agentes desempenham com desenvolturas diferentes. A Teoria de Prática difundiu-se pelo espaço epistêmico desde a sua emergência, nos anos 70, e atualmente, abordagens relativas a ela podem ser identificadas em subcampos diversos (teoria da estratégia, antropologia política, estudos de cultura material, sociologia do consumo e neurociências). (Postill, 2010).

São duas as gerações de teóricos de prática, segundo Postill (2010). Bourdieu (1977), Certeau (1984), Foucault (1979) e Giddens (1979, 1984) constituiriam a primeira geração de teóricos, sendo atribuída a eles a fundação do que se conhece atualmente como Teoria de Prática. A fundação dessa teoria consiste no fato desses pensadores terem encontrado o caminho do meio entre o individualismo metodológico e o holismo metodológico, em termos de liberar "a habilidade humana de atuar no mundo e transformá-lo - das constrições de modelos estruturalistas enquanto evitavam a armadilha do individualismo metodológico" (Postill, 2010, p. 7). Por outro lado, uma segunda geração é identificada por Postill (2010), estando ocupada em propor novas extensões a essa base teórica. Quanto a isso, Ortner (1984, 2006), Schatzki (1996), Schatzki et al. (2001), Reckwitz (2002) e Warde (2005) configuram como expoentes da mesma e, de acordo com Postill (2010), continuaram o tensionamento da centralidade do corpo humano à prática ao dedicarem-se a questões de Cultura e História, bem como, a desenvolver novos conceitos.

Segue a definição de prática, conforme Reckwitz (2002, p. 249250): 


\begin{abstract}
Prática é um tipo de comportamento rotinizado que consiste em muitos elementos interconectados entre si: formas de atividades corporais, formas de atividades mentais, "coisas" e seu uso, um conhecimento prévio na forma de compreender como se faz algo, estados de emoção e de conhecimento motivacional. Prática forma, por assim dizer, um bloco cuja existência necessariamente depende da existência e da interconexão específica desses elementos.
\end{abstract}

Ainda na introdução de Theorising Media and Practice (Postill, 2010), faz uma série de considerações justificando a pertinência de se relacionar estudos de mídia e teoria de prática. Um dos motivos levantados é que, embora a Teoria de Prática tenha sido o suporte principal da teoria social por 30 anos, teve, nesse período, um impacto limitado nos estudos de mídia.

Mídia na vida cotidiana, mídia e corpo e produção de mídia são eixos de análise pelos quais é possível se endereçar novas questões via Teoria de Prática, de acordo com Postill (2010). Nesse sentido, entende-se que a mídia serve como campo de observação do jogo cultural cotidiano de (re)produção e mudança, cujos praticantes exibem graus e demonstram qualidades diferentes de saberfazer incorporado, auto-disciplina e compromisso com relação aos jogos do campo em questão (Postill, 2010). Postill (2010) ainda complementa que esses campos são formados por pessoas capazes de realizar determinadas práticas, via competição ou cooperação, em troca dos mesmos prêmios e recompensas: dinheiro, prazer, reconhecimento, entre outros.

\title{
Comunicação digital como prática de mídia
}

Destaca-se, aqui, dois estudos sobre mídia digital entendida como prática: a contribuição de Bird (2010) sobre audiências de mídia em torno de fãs e de momentos mediados; e o artigo de Ardévol e outros (2010) sobre práticas de criação cultural, envolvendo análise de machinimas ${ }^{1}$ e produção de vídeos disponibilizados na internet e apropriados pelos meios de comunicação convencionais.

Ao reconhecer o caráter ativo das audiências, Bird (2010, p. 86) considera o termo audiência de mídia mais adequado para definir as práticas de mídia atuais do que a expressão "resposta de audiência" largamente utilizada, ao menos, pelos antropólogos da Mídia. Para Bird (2010), o fato de fãs, mais do que apenas assistirem ou falarem sobre seus ídolos e suas atividades, atuarem criando fan-fictions, vídeos de mash up, e organizarem conferências mostram formas imprevisíveis de articulação ativa destes com a mídia.

1 Machinimas é arte de fazer vídeos a partir de videogames. (Picard, 2007, p.1). 
De forma abreviada, pode-se dizer que a abordagem chamada de momento mediado por Bird (2010) interpreta a difusão e recriação de vídeos na internet elaborados a partir de situações de mídia inusitadas como expressão de uma crítica a um mundo saturado de mídia, em que se espera que todos saibam como proceder diante das câmeras ou de um microfone.

Ardévol e outros (2010) interessam-se pelo debate de práticas de mídia pelo foco das mudanças referentes às esferas de produção e consumo no contexto da mídia digital. Os autores (2010) partem da noção de prática de Schatzki (2001), segundo o qual prática é um conjunto de ações que requer formas de fazer e de dizer, para investigar o que as pessoas fazem com a mídia de modo que se obtenha respostas não previstas pelas teorias de audiência e recepção. Este artigo parte da premissa das práticas de consumo, conforme Warde (2005), a ser destacado a seguir, e consiste em três estudos de caso a partir de produtos audiovisuais gerados pelos usuários que, de uma forma ou outra, tratam das apropriações que as pessoas fazem de produtos culturais da mídia de massa, bem como a produção de conteúdo e a criação de suas próprias audiências que, por sua vez, também afetam a produção de mídia convencional. Nessa nova paisagem de mídia, a distribuição via internet e as práticas de compartilhamento de conteúdo confundem as fronteiras entre produção e recepção.

Pode-se dizer que os dois artigos citados nesta seção partem da premissa da audiência ativa e das consequências dessa condição na atual ecologia de mídia. No entanto, é interessante notar que, no segundo caso, o fato de se focar em produção e consumo como práticas complementares e, por vezes, simultâneas, relacionadas à mídia digital, chama a atenção para a questão da performance dos usuários. De certa forma, a proposta de um conceito de consumo digital guarda alguma semelhança com essa abordagem.

\section{Consumo digital e teoria de prática ${ }^{2}$}

Nesta seção, aplica-se o conceito de consumo de Warde (2005) a consumo digital. Para que se entenda esse conceito impõe retomar a apropriação que o autor faz da teoria de Schatzki e outros (2001). Para Schatzki (1996), citado por Warde (2005), a prática pode ser interpretada tanto como uma entidade coordenada quanto como performance. São exemplos de práticas enquanto entidades coordenadas cozinhar, votar, divertir-se, negócios, entre outras. Para que fazeres e dizeres formem uma prática constituinte de um nexo, pressupõe-

2 Warde (2005) utiliza o termo Teorias de Prática, no plural, enquanto que Postill (2010) utiliza o termo no singular. Neste artigo, escolhemos utilizar o termo no singular. 
se que essas noções estejam interconectadas. Parafraseando Schatzki (1996), Warde (2005) propõe que essas possibilidades de criação de nexo sejam as seguintes: 1) entendimentos, no sentido de se saber o que deve ser dito e o que deve ser feito; 2) procedimentos, através de regras, preceitos e instruções; e 3) engajamentos, que abrangem fins, projetos, tarefas, finalidades, crenças, emoções e humores.

Quanto a isso, Warde (2005) faz notar que, ao pressupor fazeres e dizeres, o entendimento de práticas como entidade coordenada deve compreender a análise das práticas em si e de suas representações. Já prática como performance refere-se à realização das práticas, a performance de fazeres e dizeres que tornam reais e sustentam práticas no sentido de nexo, uma vez que a reprodução de nexo requer uma representação regular. Ou seja, Warde (2005) destaca que práticas são entidades coordenadas, mas que também requerem a performance para a sua existência. E que a performance também demanda uma prática. O autor (2005) salienta, entretanto, que existem apropriações nas práticas, de modo que, em uma mesma prática, as performances podem não ser as mesmas.

Warde (2005) também destaca que Schatzki (1996) diferencia práticas dispersas de práticas integradoras. As práticas dispersas se dão dentro e através de diferentes subcampos (exemplo, descrição, explicação, questionamento, relato, exame e imaginação). Já as práticas integradoras referem-se a práticas específicas em determinados domínios da vida social (como, por exemplo, cozinhar e negócios), pressupondo, por vezes, práticas dispersas. Para Warde (2005), as práticas integradoras despertam mais o interesse de uma sociologia do consumo.

Com isso, consumo sob a perspectiva das Teorias de Prática significa o seguinte:

Tendo isso em mente, entendo consumo como um processo pelo qual agentes envolvem-se na apropriação e apreciação, seja por razões contemplativas, expressivas ou utilitárias, de bens, serviços, performances, informação ou ambiente, tenham eles pago por isso ou não, sobre os quais o agente tenha algum grau de poder. Desse modo, consumo não é uma prática em si, mas um momento de quase toda prática (Warde, 2005, p. 137).

Portanto, no contexto das teorias de prática, o consumo se dá dentro e em função de práticas, de forma que estas requerem o consumo de determinados produtos e serviços para serem possíveis, bem como determinados conhecimentos por parte de quem as pratica. 
Prática, por assim dizer, requer que aqueles que a praticam com competência se utilizem dos serviços requeridos, possuam e comandem a capacidade de manipular as ferramentas apropriadas e dediquem um nível adequado de atenção à condução da prática. Isto é, naturalmente, além da demonstração de uma compreensão comum, know-how e comprometimento com o valor da prática (Warde, 2005).

Dessa forma, Warde (2005) propõe que possíveis gratificações são decorrentes não do consumo em si, mas sim, da prática que o inspira. Por outras palavras, o consumo em si dificilmente oferece esse tipo de recompensa, sendo que esta é mais comumente associada à performance ligada a uma determinada prática que, por sua vez, requer posse ou acesso de determinados bens e serviços para se efetivar.

De acordo com a premissa da Teoria de Prática para o entendimento do consumo, conforme Warde (2005), se consumo não é em si uma prática, mas viabilizador de práticas, qual seria a prática para a qual ele contribui em comunicação digital?

Em se tratando de consumo digital, entende-se que a prática que ele viabiliza é a da socialização online. Nesses termos, a socialização online como prática requer que atores tenham acesso à internet e habilidades para utilizar os sites de redes sociais, o que é cada vez mais comum diante da facilidade de manejo dessas ferramentas e o baixo custo envolvido nesta operação. Dados recentes de acesso e de tempo dedicados a esses sites são indicativos do nível de atenção a essa prática, ainda que não a expliquem. Acredita-se que a justificativa para a socialização online satisfazer uma condição de prática, ao pressupor entendimentos comuns, saber-fazer e comprometimentos com os valores inerentes à definição de prática está na centralidade que a questão da performance conhece nos dias de hoje.

Nesse sentido, Ehrenberg (2010) reconhece no cenário contemporâneo uma sensibilidade propícia à superação pessoal do indivíduo, em termos da exigência de que este acesse a sua individualidade por meio da ação. $O$ contexto que autor (2010) identifica como uma nova sensibilidade contemporânea, de acordo com a qual o homem deve tornar-se empreendedor de si, seria um cenário de instabilidade constante, em função do esfacelamento do Estadoprovidência. Nesse sentido, mais do que valor e princípio de ação, o empreender passa a ser um sistema de normas que se endereça a todos. Como expressão desse quadro, configura-se a emergência do esporte-aventura, sinalizando modelos de ação (rapidez de adaptação, mudança permanente, flexibilidade psíquica e corporal). Ser bem-sucedido, aqui, passa a ser "poder inventar seu 
próprio modelo, desenhar sua unicidade, ainda que idêntica a de todos os outros". Com isso, percebe-se a relação inédita entre a identidade pessoal e a visibilidade social, e entre esta e a autenticidade, conforme as palavras do autor:

Ter por ambição tornar-se a si mesmo, identificar ser si mesmo e ser o melhor, é assimilar um código "da autenticidade" ou da identidade a um código de visibilidade. É fazer entrar na intimidade psíquica o modelo público da performance: a identidade depende de uma conquista semelhante a um recorde ou a um mercado. (Ehrenberg, 2010, p. 51).

Dessa forma, a construção de identidade não mais se filiaria a pertencimentos coletivos tradicionais, passando a consistir em projeto voltado ao futuro por meio de uma performance individual. Ehrenberg (2010) ainda salienta que, nesse sentido, a meritocracia inclui a possibilidade de vencer de qualquer forma, no que se inclui o consumo, importando mais a multiplicação das formas de vencer do que o objeto de sucesso em si.

Quanto a isso, do conceito de performance de Schechner (2003), importa destacar a idéia de comportamento restaurado. Ser exibido e mostrar-se fazendo algo a alguém é a forma como Schechner (2003) entende o ato de performar. Segundo este autor (2003), qualquer experiência constituinte do desenvolvimento humano pode ser entendida como performance, tendo-se em vista a tendência de se viver de acordo com a cultura na qual estamos inseridos, o que pode ser compreendido em termos de comportamento restaurado. "O comportamento restaurado é - eu me comportando como se fosse outra pessoa, ou eu me comportando como me mandaram ou eu me comportando como aprendi" (Schechner, 2003, p. 5). A internet e a mídia contribuiriam, segundo o autor (2003, p. 5), para que se vivesse "sequências de performances conectadas", já que elas próprias produzem e reproduzem situações sociais. Pode-se relacionar a ideia de comportamento restaurado de Schechner (2003) a da finalidade atribuída às práticas por Postill (2010) quanto às pretensões do indivíduo em relação a atingir uma certa segurança ontológica em um mundo instável.

Boyd (2007a) adapta a perspectiva de Goffman (1975) em relação à socialização online em sites de redes sociais. Para Boyd (2007a), citada por Nascimento (2010), a escolha de como se comunicar e de que tipos de informações revelar, a fim de causar impressões em uma audiência, tornam a performance em sites de redes sociais mais facilmente gerenciável. Assim, Boyd 
(2007a) afirma que perfis nesses sites desempenham a função de performances virtuais identitárias.

Sites de redes sociais, por sua vez, são espaços apropriados para expressar redes sociais na internet. Recuero (2009) vale-se da definição de Boyd e Ellisson (2007) no que diz respeito a esses sites:

Sites de redes sociais foram definidos como aqueles sistemas que permitem: i) a construção de uma persona através de um perfil ou página pessoal; ii) a interação através de comentários; e iii) a exposição pública da rede social de cada ator. (Boyd e Elisson, 2007, p.1)

Ao mencionar os públicos mediados, Recuero (2012) retoma Boyd (2007b) e lista as seguintes características para as suas interações: persistência (referese ao fato de que expressões online possam ser automaticamente gravadas e arquivadas); replicabilidade (diz respeito à duplicação de conteúdos digitais em conversações online); audiências invisíveis (ao contrário de interações face-aface, em que a audiência se dá via presença física, em interações online pode-se perceber a existência de grupos, mas não sua presença em si); e buscabilidade (característica de se poder buscar e recuperar informações e expressões).

Pode-se concluir, a partir de Recuero (2009) que a apropriação social dos sites de redes sociais pressupõe a construção de valores que, por sua vez, podem auxiliar a percepção de capital social. A pertinência da performance na abordagem de consumo aqui proposta tem relação evidente com essa percepção de capital social. Nesse sentido, sites de redes sociais "são capazes de construir e facilitar a emergência de tipos de capital social que não são facilmente acessíveis aos atores sociais no espaço off-line" (Recuero, 2009, p. 107), como, por exemplo, um número significativo de seguidores no Twitter, pode conferir visibilidade, reputação e popularidade tanto no ambiente online quanto no off-line para determinado ator. A construção desses valores e seus desdobramentos em termos de capital social em sites de redes sociais, necessariamente, são dependentes da performance do usuário em termos de socialização online (frequência e qualidade de postagens, comentários, etc.).

Uma vez que a socialização online foi identificada como prática pelos preceitos da Teoria de Prática, com apoio de estudos que ultrapassam os domínios dessa abordagem teórica, cabe verificar que papel desempenha o consumo digital nesse esquema. Para isso, é preciso, antes, conceituar consumo digital. 
Sendo assim, entende-se o consumo como fator de performance na prática da socialização online, de modo que consumo, nesse sentido, consiste no acesso, na produção, na disponibilização e no compartilhamento de conteúdo digital, envolvendo ou não a alocação de recursos financeiros para tanto. Essa interpretação de consumo no âmbito digital prevê as seguintes características:

1) Acesso a e criação de conteúdos digitais (texto, foto, imagens, som, vídeo, etc.), bem como sua disponibilização (via uploads, compartilhamentos, etc.) em sites de redes sociais. Exemplos disso seriam desde a publicação de uma postagem em blog, de um comentário no Facebook, quanto a disponibilização de um vídeo no You Tube. Esse caráter ativo dos usuários coincide com as abordagens de Bird (2010) e de Ardévol e outros (2010), conforme disposto anteriormente. Nesse caso, deve-se destacar o comentário feito por Ardévol e outros (2010) da necessária dissociação entre consumo e compra feita por Warde (2005, p. 137) e, também, discutida em artigo anterior (2013).

2) Identificação do usuário ou grupo de usuários: as ações anteriormente referidas só terão validade em termos de performance caso se possa identificálas. Portanto, as ações de atores que não se identificam não são contempladas por esse conceito, uma vez que, embora atuem no sentido do consumo de conteúdo digital, nos termos propostos, não o utilizam como fator de performance. Portanto, a possibilidade de se buscar e recuperar conteúdo digital nesses sites é fundamental para que o consumo importe em termos de performance.

3) Podem envolver ou não a alocação de recursos financeiros: Por alocação de recursos financeiros entende-se compras de bens e acesso a serviços mediante pagamento ou doações. Em artigo anterior (2013) identificou-se mecanismos de exposição de informações do usuário disponibilizada por um aplicativo referente a doações para a WikiLeaks. Quanto a compras, as blogueiras de moda são um exemplo em termos de viabilizar ações nesse sentido uma vez que dispõem links para lojas virtuais, sejam as suas próprias, sejam de outras vias links patrocinados. Retomando o comentário feito no item 1, ainda que consumo digital possa ser dissociado de compra, pode, por outro lado, estar identificado com a mesma.

Cabe destacar também que, da mesma forma que o constatado por Ardévol e outros (2010), este conceito prevê a produção e o acesso a conteúdos digitais como práticas complementares e, às vezes, simultâneas, situação também prevista nos estudos localizados em ocasião do levantamento do estado da arte sobre performance e consumo. Frente a isso, é que se torna pertinente afirmar que a socialização online é a prática comum entre essas diferentes ações 
de modo que se possa interpretá-las como consumo digital em sites de redes sociais.

\section{Considerações finais}

Levando-se em conta o enquadramento da Teoria de Prática, ao assumir que o consumo digital não é uma prática em si, o consumo em sites de redes sociais parece consistir no elemento viabilizador da prática da socialização online e seria, em função disso, elemento-fator de performance. Nesses termos, a construção de valores por parte do ator social, que se dá via o consumo de conteúdo digital, tal qual fora proposto, e a percepção de capital social decorrente disso, de acordo com Recuero (2009), correspondem facilmente aos fins da performance segundo Boyd (2007). Com isso, reconhece-se, também, a performance em Ehrenberg (2010, p. 48), na medida em que o acesso à individualidade dependeria da passagem à ação, nesse caso, via manipulação de conteúdo digital. Ou seja, é a qualidade de manipulação desse conteúdo (consumo digital) um dos fatores que designa a performance de dado ator social na prática de socialização online. Pode-se acrescentar, ainda, tal qual pontua Postill (2010), que essa prática se dá via competição ou cooperação, visando dinheiro, prazer e reconhecimento, entre outras recompensas. Vale ressaltar que a abordagem de consumo digital aqui proposta pressupõe o grau de poder por parte do agente, conforme Warde (2005) em seu conceito de consumo.

Warde (2005) elaborou o seu conceito de consumo tendo como base as práticas integradoras, de acordo com Schatzchi (1996), que dizem respeito à expertise em práticas específicas. No entanto, ao se considerar a socialização online como prática viabilizada pelo consumo de conteúdo digital, pode-se assumi-la tanto com relação a práticas dispersas quanto às integradoras, uma vez que em ambas se reconhece as repercussões da performance.

No âmbito da Teoria de Prática, consumo digital, conforme aqui proposto, pode ser visto como uma derivação do conceito de consumo de Warde (2005) e, com isso, ser identificado como decorrente da obra dessa segunda geração de autores, da qual Warde (2005) faz parte, segundo Postill (2010), e que se dedica a propor novas extensões teóricas a essa abordagem.

Frente a isso, acredita-se que os estudos de comunicação digital associados à performance, que foram citados na primeira seção deste artigo, podem ser contemplados por esta perspectiva de consumo digital por atender às especificações elencadas, caso essa abordagem se mostre pertinente para os objetivos dos mesmos. Por outro lado, esse conceito só é aplicável se o ator social se identifica no processo de socialização online. Com isso, provavelmente, 
os usos de conteúdo digital ligados a questões ilegais e criminosas devem ser analisados por meio de outros modelos teóricos.

Por fim, cabe ressaltar que o fato de o consumo não ser considerado uma prática em si, de acordo com a perspectiva aqui construída, de forma alguma invalida essa abordagem, seja no ambiente online, seja no ambiente off-line. Da mesma forma, não se diminui ou se secundariza o papel do consumo digital com relação à prática de socialização online pelo fato de o primeiro viabilizar a segunda. Trata-se, apenas, de uma abordagem possível pelo viés da Teoria de Prática, a qual pressupõe competência na utilização dos serviços requeridos, acesso e capacidade de se manipular ferramentas apropriadas, além de determinado grau de atenção à condução da prática (Warde, 2005), o que se aplica de modo mais evidente à socialização online. E que, por isso, permite analisar as novas configurações da performance devido à popularização dos sites de redes sociais. Nesse caso, seria válido investigar o sentido que recobre o conceito de prática amplamente utilizado nos estudos de consumo em geral.

Essa abordagem de consumo em sites de redes sociais pode e deve conhecer novos desdobramentos em função de sua aplicação em estudos de casos específicos - conforme o objeto consumido, com foco em comportamentos individual ou coletivo dos consumidores e pelo grau na expertise no uso de determinadas ferramentas de comunicação mediada pelo computador, por exemplo.

Algumas questões se impõem: em que medida o tipo de conteúdo consumido nesses espaços tem implicação com o consumo digital? De que forma um mesmo site de rede social formataria as performances dos usuários a partir de objetos de consumo diferentes? A busca por estas respostas é o que inspira a continuidade desta pesquisa.

\section{Referências}

AMARAL, Adriana. MONTEIRO, Camila. "Esses roquero não curte": performance de gosto e fãs de música no Unidos Contra o Rock do Facebook In: XXI Compós, 2012, Juiz de Fora. Anais do XXI Encontro Anual da Compós. Juiz de Fora: Universidade Federal de Juiz de Fora, p. 01-15, 2012.

Customização, viralização, e disputas nas performances e práticas de consumo subcultural nos sites de redes sociais. In: I Comunicon, 2011, São Paulo. Anais do I Comunicon. São Paulo: Escola Superior de Propaganda e Marketing. p. 1-2, 2011. 
ARDÉVOL, Elisenda; ROIG, Antoni; SAN CORNELIO, Gemma; PAGÉS, Ruth; ALSINA, Pau. Playful practices: theorising "new media"cultural production. In: BRÄUCHLER, Birgit; POSTILL, John. (Org.).Theorising media and practice. Oxford e Nova York: Berghahn, 2010.

BARBOSA, Lívia. O estudo do consumo nas ciências sociais contemporâneas. In: BARBOSA, Lívia. CAMPBELL, Colin. Cultura, Consumo e Identidade. Rio de Janeiro: Jorge Zahar, 2009.

BIRD, Elizabeth. From practice to mediated moments: the value of practice theory in the understanding of Media Audiences. BRÄUCHLER, Birgit; POSTILL, John (Org.). Theorising media and practice. Oxford e Nova York: Berghahn, 2010.

BOYD, Dannah. Why Youth (Heart) Social Network Sites: The role of Networked Publics in Teenage Social Life. In: MacArthur Foundation Series on Digital Learning Youth, Identity, and Digital Media Volume (Ed. David Buckingham). Cambridge: MIT Press, 2007a.

Social Networks Sites: Public, Privet, or What? Knowledge Tree, n. 13, v. 1, May 2007b. p. 1-7. Disponível em: <http://www.danah.org/papers/KnowledgeTree. pdf>. Acesso em: 18 fev. 2013.

; ELLISON, Nicole. Social network sites: Definition, history, and scholarship. Journal of Computer- Mediated Communication, Indianapolis, v.1, n. 13, p. 210-230, out. 2007. Disponível em: <http://jcmc.indiana.edu/vol13/issue1/ boyd.ellison.html>. Acesso em: 18 fev. 2013.

BRÄUCHLER, Birgit; POSTILL, John (Org.). Theorising media and practice. Oxford e Nova York: Berghahn, 2010.

CAMPBELL, Colin. Eu compro, logo sei que existo. As bases metafísicas do consumo moderno. In: BARBOSA, Lívia. CAMPBELL, Colin. Cultura, Consumo e Identidade. Rio de Janeiro: Jorge Zahar, 2009.

CORREA, Vanessa. Práticas de consumo online em blogs: estudos de caso do Blog da Thássia e do Blog Garotas Estúpidas. 2012. 95 f. Monografia. (Graduação em Publicidade e Propaganda). Curso de Publicidade e Propaganda, Universidade Feevale, Novo Hamburgo, 2012.

CHRISTENSEN, Toke; ROPKE, Inge. Can Practice Theory inspire studies of ICTs in everyday life? In: BRÄUCHLER, Birgit; POSTILL, John (Org.). Theorising media and practice. Oxford e Nova York: Berghahn, 2010.

EHRENBERG, Alain. 0 culto da performance. Da aventura empreendedora à depressão nervosa. Aparecida, SP: Idéias \& Letras, 2010. 
; ARAÚJO, Willian Fernandes. Performance e práticas de consumo online: ciberativismo em sites de redes sociais. Revista Famecos, Porto Alegre, v. 20, n. 2, p. 472-494, dez. 2013.

MONTARDO, Sandra Portella. Consumo digital e Teoria de Prática: uma abordagem possível. In: XXXVI Congresso Brasileiro de Ciências da Comunicação, 2013, Manaus. Anais do XXXVI Congresso Brasileiro de Ciências da Comunicação. Manaus: Universidade Federal do Amazonas, 2013, pp. 1-14.

NASCIMENTO, Liliana.Exposição e performance em sites de rede sociais. In: IV Simpósio Nacional da Associação Brasileira de Pesquisadores em Cibercultura (ABCiber), 2010, Rio de Janeiro. Anais do IV Simpósio Nacional da ABCiber. Rio de Janeiro: Universidade Federal do Rio de Janeiro, p. 1-17, 2010.

ORTNER, Sherry Beth. Theory in Anthropology Since the Sixties. Comparative Studies in Society and History, n. 26, vol. 1, pp. 126-66, 1984.

Anthropology and Social Theory: Culture, Power and the Acting Subject. Durham, NC: Duke University Press, 2006.

PICARD, Martin. Machinima: Video Game As An Art Form? Loading..., Burnaby, vol. 1, n. 1, 2007. p .1-6. Disponível em: <http://journals.sfu.ca/loading/index.php/ loading/article/viewArticle/17>. Acesso em: 9 dez. 2013.

POSTILL, John. Introduction: Theorising media and Practice. In: BRÄUCHLER, Birgit; POSTILL, John (Org.) Theorising Media and Practice. Oxford e Nova York: Berghahn, 2010.

RECKWITZ, Andreas. Toward a Theory of Social Practices: A Development in Culturalist Theorizing. European Journal of Social Theory, n. 5: pp. 243-63, 2002.

SÁ, Simone de; POLIVANOV, Beatriz. Materialidades da Comunicação e presentificação do sujeito em sites de redes sociais. In: XXI Compós, 2012, Juiz de Fora. Anais do XXI Encontro Anual da Compós. Juiz de Fora: Universidade Federal de Juiz de Fora, p. 1-17, 2012.

; HOLZBACH, Ariane. \#u2youtube e a performance mediada por computador. In: XIX Compós, 2010, Rio de Janeiro. Anais do XIX Encontro Anual da Compós. Rio de Janeiro: Pontifícia Universidade Católica do Rio de Janeiro, p. 1-18, 2010.

SCHATZCHI, Theodor. Introduction: Practice Theory. In: SCHATZCHI, Theodor ;KNORR CETINA, K.; von SAVIGNY, E. (Orgs.). The Practice turn in Contemporary Theory. London: Routledge, 2001.

; KNORR CETINA, K.; von SAVIGNY, E. (Orgs.). The Practice turn in Contemporary Theory. London: Routledge, 2001. 
Social Practices: a Wittgensteinian Appproach to Human Activity and the Social. Cambridge: Cambridge Univerity Press, 1996.

RECUERO, Raquel. A conversação em rede. Comunicação mediada pelo computador e redes sociais na internet. Porto Alegre: Sulina, 2012.

Redes Sociais na Internet. Porto Alegre: Sulina, 2009.

SCHECHNER, Richard. O que é performance. O Percevejo, n. 12, pp. 1-10, 2003.

WARDE, Alan. Consumption andTheories of Practice. Journal of Consumer Culture.Vol. 5, n. 2, p. 131-153, 2005. Disponível em: <http://www.espm.br/Pesquisadores versao1/CAEPM/Documents/Consumption\%20and\%20Theories\%20of\%20 Practice.pdf $>$. Acesso em: 4 fev. 2013.

Recebido em: 21/10/2015

Aceito em: 09/12/2015

Endereço da autora:

Sandra Portella Montardo <sandramontardo@feevale.br>

Universidade Feevale

Rodovia RS 239, 2755 - Vila Nova

CEP 93525-075

Novo Hamburgo, RS - Brasil 